International Journal of Education (IJE) Vol.8, No.2, June 2020

\title{
ACADEMIC EXPECTATION STRESS, Psychological Capital, Humour Style AND STUDENT WELLBEING
}

\author{
Nicole Johnston and Tony Cassidy \\ Ulster University, Northern Ireland
}

\begin{abstract}
A well established and accepted inevitability has emerged that students are vulnerable to stress throughout their academic journey, negatively influencing their psychological wellbeing. The current study explored the relationship between academic expectation stress and psychological wellbeing in 212 undergraduate students (44 males and 168 females) age ranging between 18-41 years old. Psychological capital and humour use were also explored to identify the potential mediating roles played by these variables within the academic expectation stress and wellbeing relationship. Findings demonstrated support for psychological capital and humour styles in mediating the relationship between academic expectation stress and student wellbeing. Relationships between these variables previously received little research attention, therefore this study sheds light on the potential stress buffering effect which could inform future interventions in a bid to aid coping and improve wellbeing in students.
\end{abstract}

\section{KEYWORDS}

Academic expectations stress; Psychological capital; Humour; Wellbeing

\section{INTRODUCTION}

While academic stress is well known, academic expectation stress is less well researched (Fawzy\& Hamed, 2017). Evidence shows that while these expectations are mainly imposed by parents (Deb, Strod, \& Sun, 2015; Sangma et al., 2018), they can be self-imposed by students (Ramachandiran, \&Dhanapal, 2018), and may also come from teachers (Bedewy\& Gabriel, 2015). When these expectations overwhelm the student's ability to cope, they become vulnerable to experiencing academic expectation stress (Ang \& Huan, 2006; Yamamoto \& Holloway, 2010).

Researchers have attempted to identify the moderating factors in stress, that allow individuals to cope better, thus lessening the detrimental impact on their mental wellbeing. Positive psychology has highlighted the role of Psychological Capital (Psycap) in coping with adversities (Luthans, Luthans \& Luthans, 2004). Luthans, Youssef and Avolio (2007) define PsyCap as a state-like positive psychological form that is individual to each person and consists of four components: self-efficacy, hope, optimism and resilience.

Studies associate PsyCap with greater academic engagement and increased cognitive, emotional, psychological, and social wellbeing in a sample of Filipino (Datu\& Valdez, 2016), Chinese (Quingguan\&Zongkui, 2009), Indian (Gautam, Ningthoujam\& Singh, 2019) and UK students

DOI: $10.5121 /$ ije.2020.8202 
International Journal of Education (IJE) Vol.8, No.2, June 2020

(Poots \& Cassidy, 2020). Research suggests PsyCap can be utilised by students to help them cope with various challenges they face academically, self-efficacy may aid motivation and drive effort to succeed, optimism can provide students with positive attributions about tasks at hand, resilience and hope can be used to maintain this motivation to achieve and help cope with stressors (Ortega-Maldonado \&Salanova, 2018).

Use of humour has been found to have a beneficial impact on wellbeing and a buffering effect on stress (Richards \& Kruger, 2017; Wellenzohn, Proyer\& Ruch, 2016). From a positive psychological perspective, humour was perceived as a positive trait (Peterson \& Seligman, 2004) or positive quality that can be utilised or strengthened to enhance wellbeing and promote resilience by encouraging cognitive reappraisal of stressful circumstances (Kuiper, 2012). More recent research has focused on differing styles of humour and suggested that depending on style, humour can have both p[ositive and negative effects (Dowling, Hockenberry \& Gregory, 2003; Kuiper \&Borowicz-Sibenik, 2005; Martin, 2007). This framework was introduced by Martin, Puhlik-Doris, Larsen, Gray, and Weir (2003) who claimed there are two constructs that make up humour use: benign humour use and harmful humour use. The two dimensions were further divided into four humour styles, two being classed as adaptive benign (affiliative and selfenhancing) humour use and two being classed as harmful maladaptive (self-defeating and aggressive) humour use (Martin et al., 2003).

From the literature reviewed above a model of the potential relationship between academic expectation stress, PsyCap,humour, and wellbeing has been proposed.

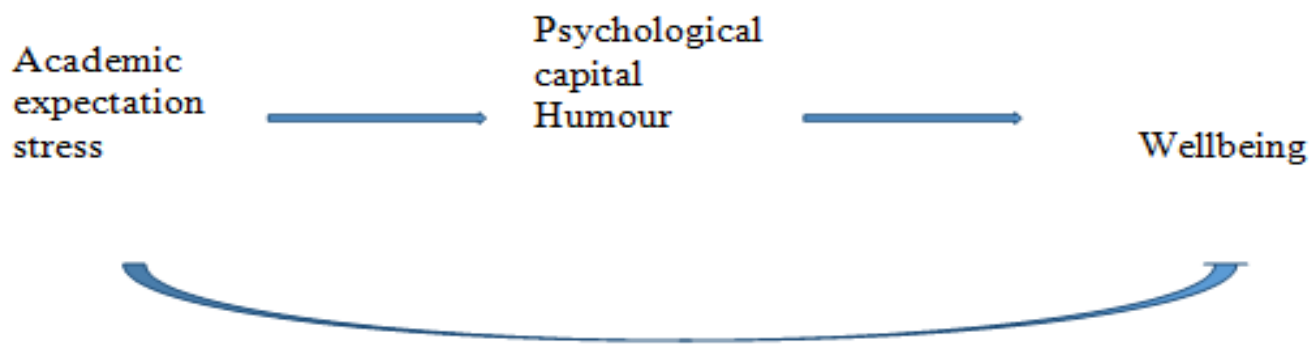

Figure 1: Proposed Model of the role of psychological capital and humourin wellbeing in students.

This study therefore aims to test the model proposed in Figure 1.

\section{METHOD}

\subsection{Design}

This study employed a cross-sectional survey design with self-report questionnairedata collection to explore the relationship between academic expectation stress, psychological capital, use of humour, and mental wellbeing.

\subsection{Participants}

Participants $(n=212)$ were undergraduate students both male $(n=44)$ and female $(n=168)$, aged between 18 and 41 . 
International Journal of Education (IJE) Vol.8, No.2, June 2020

\subsection{Materials}

Participants completeddemographic questions on sex, and age, and and the following standard measures.

The Academic Expectation Stress Inventory (AESI) (Ang, \& Huan, 2006), contains nine items that assess the level of academic stress derived from self-expectations and those of parents and teachers. Within this scale each item is rated on a 5-point Likert scale that ranges from $1=$ Never True to5 = Almost Always True. These summed scores were used to determine the level of academic stress, with higher scores reflective of higher stress levels. Ang and Huan (2006) report the AESI to be both a valid and reliable tool that has been used within the adult population. The Cronbach's alpha for this scale in this study is 0.91 .

The Warwick Edinburgh Mental Well-being Scale-short form (Tennant et al., 2007) which is made up of seven positively worded items that relate to the different aspects of positive mental health. Each item was rated based on the experience of the respondent over the past two weeks, with items being ranked on a 5 -point Likert scale ranging from $1=$ None of the Time to $5=$ All of the Time. The summed item scores were used to determine the level of positive mental wellbeing, with a higher score indicative of a higher level of positive mental well-being. The Cronbach's alpha for the scale in this study is 0.93 .

Psychological Capital, defined by Luthans, Youssef, and Avolio (2015) is an individual's positive psychological state of development that is made up of four constructs; Resilience, Hope, Optimism and Self- Efficacy. A total score on Psychological Capital obtained by summing these four constructs is used in analysis. The construct has been commended by Luthans et al (2015) s a higher order construct comprising 4 supporting constructs and has been used as a composite in the literature.

Resilience is assessed using the Brief Resilience Scale (BRS)(Smith et al., 2008). The BRS contains six items and scores range from $1=$ Strongly Disagree to $5=$ Strongly Agree. The mean of the added scores were then used to indicate resilience, the higher the summation score, the higher the level of resilience. The Cronbach's alpha for the current study was 0.69 .

Hope is measured by Snyder et al. (1997) Hope Scale. This scale is composed of eight items utilised to assess hopeful thinking. Item scores were added with higher scores denoting higher levels of hope. The Cronbach's alpha for the scale in this study was 0.92 .

The Revised Life Orientation Test (LOT-R) is a six item scale that was used to measure dispositional optimism (Scheier, Carver, \& Bridges, 1994). The Cronbach's alpha for the scale in this studywas 0.76 .

Self-Efficacy was measuredusing the General Self-Efficacy scale (GSE) (Schwarzer, \& Jerusalem, 1995).The summed scores yielded a self-efficacy score, with higher scores denoting higher levels of perceived self-efficacy. Cronbach's alpha in this study was 0.76 .

Humour was assessed using the Humour Styles Questionnaire (HSQ) (Martin, Puhlik-Doris, Larsen, Gray \& Weir, 2003) which focuses on four areas in which individuals utilise humour, these include: to boost oneself (Self-Enhancing), to improve one's relationship with others 
International Journal of Education (IJE) Vol.8, No.2, June 2020

(Affiliative), to boost one's self at the expense of another (Aggressive) and finally, using humour to boost relationships with others at the expense of oneself (Self-Defeating). It is a self-report questionnaire, comprised of 32 items, which are scored on a 7-Point Likert Scale ranging from 1 ("Totally Disagree") to 7 ("Totally Agree") (Proctor, 2017). Internal consistency coefficient for this scale ranges from 0.77 to 0.81 and test-retest correlations of 0.80 to 0.85 (Martin et al. 2003).

\subsection{Procedure}

Once ethical approval had been granted by the University Research Ethics Committee the questionnaire was uploaded onto Qualtrics Software. An e-mail containing a link to the questionnaire was sent to 400 students in the Faculty of Health Science. On clicking the link participants were taken to the online survey where they were presented with an information sheet and asked to tick a box indicating consent. In total 212 participants completed the survey.

\section{ReSUlts}

The aim of this study was to explore the relationship between academic expectation stress and wellbeing, and the potential mediating effect of the variables psychological capital (PsyCap), and humour, on this relationship and therefore, ultimately to test the model proposed in Figure 1.

Table 1: Means, standard deviations, and correlations for study variables

$\begin{array}{lcccccccc}\text { 1. Age } & \text { Mean (SD) } & 1 & 2 & 3 & 4 & 5 & 6 & 7 \\ \text { 2. Academic expectation } & 22.58(5.37) & & & & & & & \\ \text { stress } & 3.43(1.02) & -.16^{*} & & & & & & \\ \text { 3. Psychological Capital } & 22.13(5.09) & .17^{*} & -.20^{* *} & & & & \\ \text { 4. Affiliative humour } & 5.69(0.79) & .01 & .09 & .11 & & & \\ \text { 5. Self-enhancing humour } & 4.42(1.04) & .05 & -.35^{* *} & .06 & .44^{* *} & & & \\ \text { 6. Aggressive humour } & 3.49(1.08) & -.02 & -.25^{* *} & .02 & .21^{* *} & .21^{* *} & & \\ & & & & & & & & \\ \text { 7. Self-defeating humour } & 4.08(1.34) & -.07 & .12 & .12 & .09 & -.04 & .38^{* *} & \\ \text { 8. Wellbeing } & 21.98(5.40) & -.05 & -.47^{* *} & .44^{* *} & .26^{* *} & .47^{* *} & -.02 & -.09\end{array}$

*. Correlation is significant at the 0.05 level (2-tailed). **. Correlation is significant at the 0.01 level (2-tailed).

The first stage in analysis involved calculating some descriptive statistics and correlations as shown in Table 1.

As predicted by the model in Figure 1 there was a negative correlation between academic stress and wellbeing, which was statistically significant $(\mathrm{r}(212)=-.47, p<.001)$. Results from Table 1 also suggest a statistically significant positive correlation between psychological capital and wellbeing $(\mathrm{r}(212)=.44, p<.001)$. while also indicating a negative correlation, which was also statistically significant between academic stress and psychological capital (r $(212)=-.20, p$ 
International Journal of Education (IJE) Vol.8, No.2, June 2020

$<.001$ ). In terms of humour style there were positive correlations between affiliative humour ( $\mathrm{r}$ $(212)=.26, p<.001)$ and self-enhancing humour $(\mathrm{r}(212)=.47, p<.001)$ and wellbeing. Aggressive and self-defeating humour did not correlate with wellbeing.

In order to further analyse these findings a hierarchical multiple regression analysis (HMRA) was performed to construct a path model of wellbeing.

On step 1 the demographic variables of sex and age were entered as independent variables. On step 2 academic stress was added as an independent variable. On step 3 psychological capital was added, and finally on step 4the dimensions of humour style were entered as shown in Table 2.

Table 2: HMRA to identify the predictors of wellbeing.

\begin{tabular}{|c|c|c|c|}
\hline & B & SE.B & $\beta$ \\
\hline Step 1: & \multicolumn{2}{|c|}{$\mathrm{R}^{2}=.007, \mathrm{~F}(2,209)=.285, p=.752$} & \\
\hline Sex & .051 & .131 & .027 \\
\hline Age & -.007 & .010 & -.045 \\
\hline Step 2: & \multicolumn{2}{|c|}{$\mathrm{R}^{2} \Delta=.231, \mathrm{~F}(1,208)=62.65, p<.001$} & \\
\hline Sex & .059 & .115 & .031 \\
\hline Age & -.018 & .009 & $-.122^{*}$ \\
\hline Academic expectation stress & -.367 & .046 & $-.487^{4 *}$ \\
\hline Step 3: $\quad R^{2} \Delta$ & \multicolumn{2}{|c|}{$R^{2} \Delta=.140, \mathrm{~F}(1,207)=46.09, p<.001$} & \\
\hline Sex & -.005 & .105 & -.003 \\
\hline Age & -.025 & .008 & $-.176^{* *}$ \\
\hline Academic expectation stress & -.315 & .043 & $-.418^{* *}$ \\
\hline Psychological Capital & .443 & .065 & $387^{* *}$ \\
\hline Step 4: & \multicolumn{2}{|c|}{$R^{2} \Delta=.164, \mathrm{~F}(4,203)=17.98, p<.001$} & \\
\hline Sex & -.039 & .094 & -.021 \\
\hline Age & -.027 & .007 & $-.191^{* *}$ \\
\hline Academic expectation stress & -.296 & .044 & $-.392^{* *}$ \\
\hline Psychological Capital & .417 & .058 & $364^{4 *}$ \\
\hline Affiliative humour & .179 & .057 & $.183^{* *}$ \\
\hline Self-enhancing humour & .209 & .044 & $.281^{* *}$ \\
\hline Aggressive humour & -.153 & .041 & $-.215^{* 4}$ \\
\hline \multirow[t]{3}{*}{ Self-defeating humour } & -.015 & .031 & -.027 \\
\hline & $=.52$ & & \\
\hline & $p<.01$ & & \\
\hline
\end{tabular}




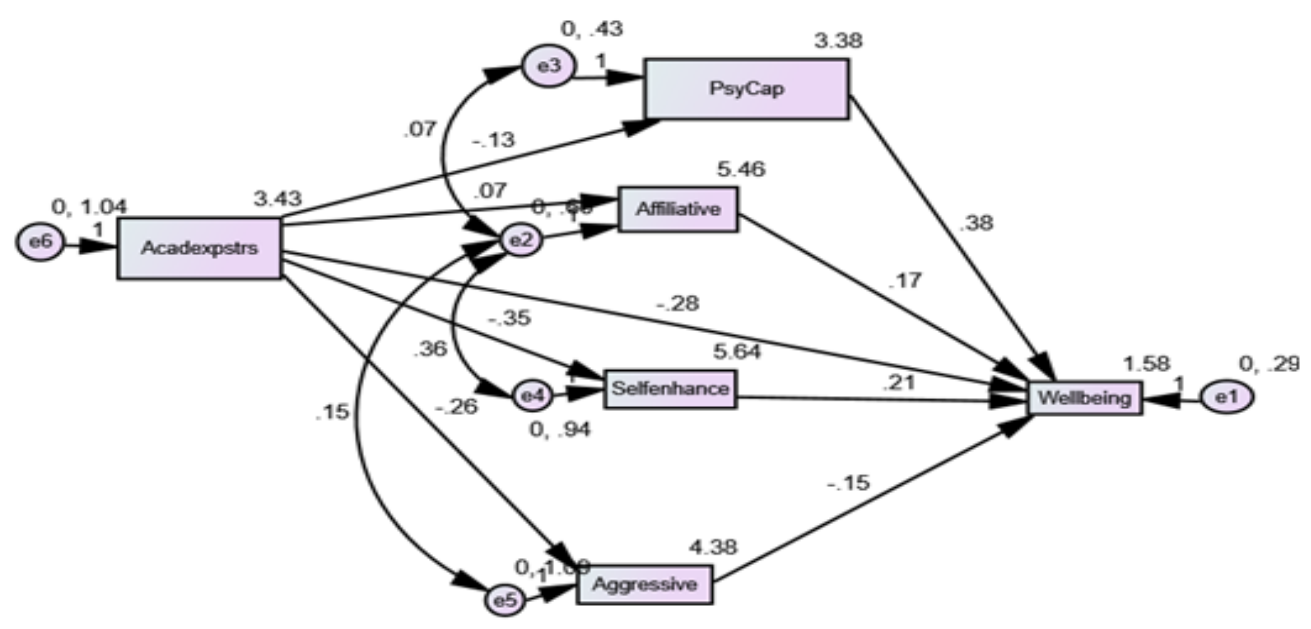

Figure 2: Path model of predictors of wellbeing: Acadexpstrs = academic exception stress; PsyCap = psychological capital

In order to test the fit of the model proposed in Figure 1AMOS 25was used as shown in Figure 2 to build and test a path model. Fit statistics for the model were chi-square $(3)=4.24, p=.237$, $\mathrm{CMIN} / \mathrm{DF}=1.413, \mathrm{GFI}=.99, \mathrm{NFI}=.99, \mathrm{IFI}=.99, \mathrm{CFI}=.99, \mathrm{RMSEA}=.04$, PCLOSE $=$ .441.This largely supports the proposed model in Figure 1.

\section{DisCussion}

This study aimed to test the proposed model as set out in Figure 1. Current findings largely supported this model, illustrating a significant negative correlation between academic stress and wellbeing and also supporting the mediating roles which the variables PsyCap, and humour play within this relationship(Sangma et al., 2018; Wellenzohn, Proyer\& Ruch, 2016).

In the current study, academic expectation stress was the most influential predictor of student wellbeing, followed by PsyCap, highlighting the significant role of academic expectation stress on wellbeing, while also emphasising the encouraging significant role of PsyCap. The significant positive correlation between PsyCap and wellbeing suggests that individuals higher in PsyCap, experienced more positive wellbeing. Additionally, the negative correlation found between PsyCap and academic expectation stress, which was supported by further analysis, highlightedPsyCaps stress buffering potential as found in previous research in academic stress (Riolli et al., 2012). This buffering effect could be explained by PsyCap's potential ability to produce more effective coping, through motivation, confidence and positive appraisals (Ortega-Maldonado \&Salanova, 2018; Riolli et al., 2012).

Using humour to cope with adverse situations shares similarities with PsyCap in that humour use may equip individuals with the necessary cognitive ability to reframe negative events (Kuiper, 2012) to view them as positive tasks rather than threats (Cann\& Collette, 2014). Further, this positive trait can be then used to maintain wellbeing throughout adversities (Peterson and Seligman, 2004). Findings from the current study demonstrate further support for the proposed model through significant positive correlations between affiliative and self-enhancing humour 
International Journal of Education (IJE) Vol.8, No.2, June 2020

and wellbeing (Wellenzohn et al., 2016). Although a wealth of research supports the positive influence affiliative humour has on wellbeing (Fritz et al., 2017; Kazarian\& Martin, 2004), research indicating significant relationships between affiliative humour and stress is relatively scarce (Holland, 2016; Richards \& Kruger, 2012).An explanation for this could be due to affiliative humour being closely associated with engagement with others to create and enhance social relationships (Peebles, 2015). Poots and Cassidy (2020) found students with more social support experienced lower stress levels. Therefore, it could be assumed that affiliative humour may play an indirect role in buffering against stress in relation to social support and the significant positive relationship with wellbeing (Bhattacharyya, Jena \& Pradhan, 2019).

In terms of aggressive humour path analysis demonstrated that higher levels of academic expectation stress along with aggressive humour use was related to lower wellbeing.This supported previous findings by Tümkaya (2011) and research indicating that using higher levels of aggressive humour correlated with academic stress, thus negatively impacting psychological wellbeing (Tsukawaki et al., 2019). It would appear that aggressive humour has a negative impact although previous research suggests that in high stress situations aggressive humour may have a short-term buffering effect (Fritz et al., 2017).

This study supportsthe role of PsyCap in buffering stress and improving wellbeing (OrtegaMaldonado \&Salanova, 2018). Further, humour styles may provide a differential impact dependant on acceptance by culture (Tsukawaki et al., 2019), the degree of stress (Fritz et al., 2017), audience variables (Kuiper, 2012) and may demonstrate indirect benefits through improved social support (Poots \& Cassidy, 2020).

\section{REFERENCES}

[1] Ang, R. P., \& Huan, V. S. (2006). Academic expectations stress inventory: Development, factor analysis, reliability, and validity. Educational and Psychological Measurement, 66(3), 522-539.

[2] Bedewy, D., \& Gabriel, A. (2015). Examining perceptions of academic stress and its sources among university students: The Perception of Academic Stress Scale. Health Psychology Open, 19. DOI: $10.1177 / 2055102915596714$

[3] Bhattacharyya, P., Jena, L. K., \& Pradhan, S. (2019). Resilience as a Mediator Between Workplace Humour and Well-being at Work: An Enquiry on the Healthcare Professionals. Journal of Health Management, 21(1), 160-176.

[4] Cann, A., \& Collette, C. (2014). Sense of humor, stable affect, and psychological wellbeing. Europe's Journal of Psychology, 10(3), 464-479.

[5] Datu, J. A. D., \& Valdez, J. P. M. (2016). Psychological capital predicts academic engagement and well-being in Filipino high school students. The Asia-Pacific Education Researcher, 25(3), 399-405.

[6] Deb, S., Strod, E., \& Sun, J. (2015). Academic Stress, Parental Pressure, Anxiety and Mental Health among Indian High School Students. International Journal of Psychology and Behavioral Sciences, 5(1), 26-34. doi:10.5923/j.jpbs.20150501.04

[7] Dowling, J. S., Hockenberry, M., \& Gregory, R. L. (2003). Sense of humor, childhood cancer stressors, and outcomes of psychosocial adjustment, immune function, and infection. Journal of Pediatric Oncology Nursing, 20(6), 271-292.

[8] Fawzy, M., \& Hamed, S. A. (2017). Psychological stress among medical students in Assiut University, Egypt. Psychiatry Research, 7(2), 46-52.

[9] Fritz, H. L., Russek, L. N., \& Dillon, M. M. (2017). Humor use moderates the relation of stressful life events with psychological distress. Personality and social psychology bulletin, 43(6), 845-859. 
International Journal of Education (IJE) Vol.8, No.2, June 2020

[10] Gautam, V., Ningthoujam, S., \& Singh, T. (2019). Impact of Psychological Capital on Well-Being of Management Students. Theoretical Economics Letters, 9(5), 1246-1258.

[11] Holland, T. (2016). Humour Styles: Predictors of Perceived Stress and Self-Efficacy with gender and age differences.

[12] Kazarian, S. S., \& Martin, R. A. (2004). Humour styles, personality, and well-being among Lebanese university students. European journal of Personality, 18(3), 209-219.

[13] Kuiper, N. A. (2012). Humor and Resiliency: Towards a Process Model of Coping and Growth. Europe's Journal of Psychology, 8(3), 475-491.

[14] Kuiper, N. A., \&Borowicz-Sibenik, M. (2005). A good sense of humor doesn't always help: Agency and communion as moderators of psychological well-being. Personality and Individual Differences, 38(2), 365-377.

[15]Luthans, F., Luthans, K. W., \& Luthans, B. C. (2004). Positive psychological capital: beyond human and social capital. Business Horizons, 45-50

[16]Luthans, F., Youssef, C. M., \& Avolio, B. J. (2007). Psychological capital: Investing and developing positive organizational behavior. Positive organizational behavior, 1(2), 9-24.

[17]Luthans, F., Youssef, C. M., \& Avolio, B. J. (2015). Psychological capital and beyond. Oxford University Press, USA

[18] Martin, R. A. (2007). The psychology of humor: An integrative approach. Elsevier.

[19] Martin, R. A., Puhlik-Doris, P., Larsen, G., Gray, J., \& Weir, K. (2003). Individual differences in uses of humor and their relation to psychological well-being: Development of the Humor Styles Questionnaire. Journal of research in personality, 37(1), 48-75.

[20] Ortega-Maldonado, A., \&Salanova, M. (2018). Psychological capital and performance among undergraduate students: the role of meaning-focused coping and satisfaction. Teaching in Higher Education, 23(3), 390-402.

[21] Peebles, D. R. (2015). The value of positive humour in the workplace (Doctoral dissertation, University of Tasmania).

[22] Peterson, C., \& Seligman, M. E. (2004). Character strengths and virtues: A handbook and classification (Vol. 1). Oxford University Press.

[23] Poots, A., \& Cassidy, T. (2020). Academic expectation, self-compassion, psychological capital, social support and student wellbeing. International Journal of Educational Research, 99, 101506.

[24] Quingquan, P., \&Zongkui, Z. (2009). Psychological capital, coping style and psychological health: an empirical study from college students. ICISE. In First International Conference on Information Science and Engineering (pp. 3391-3394).

[25] Ramachandiran, M. \&Dhanapal, S. (2018). Academic Stress Among University Students: A Quantitative Study of Generation Y and Z's Perception. Social Science and Humanities, 26 (3): $2115-2128$.

[26]Richards, K., \& Kruger, G. (2017). Humor styles as moderators in the relationship between perceived stress and physical health. SAGE Open, 7(2), 2158244017711485.

[27] Riolli, L., Savicki, V., \& Richards, J. (2012). Psychological capital as a buffer to student stress. Psychology, 3(12), 1202.

[28] Sangma, Z. M., Shantibala, K., Akoijam, B. S., Maisnam, A. B., Vizovonuo, V., \&Vanlalduhsaki. (2018). Perception of Students on Parental and Teachers' Pressure on their Academic Performance. Journal of Dental and Medical Sciences (IOSR-JDMS), 17(1), 68-75. DOI: 10.9790/0853-1701016875

[29] Scheier, M. F., Carver, C. S., \& Bridges, M. W. (1994). Distinguishing optimism from neuroticism (and trait anxiety, self-mastery, and self-esteem): a reevaluation of the Life Orientation Test. Journal of personality and social psychology, 67(6), 1063.

[30] Schwarzer, R., \& Jerusalem, M. (1995). Optimistic self-beliefs as a resource factor in coping with stress. In Extreme stress and communities: Impact and intervention (pp. 159-177). Springer, Dordrecht. 
[31] Smith, B. W., Dalen, J., Wiggins, K., Tooley, E., Christopher, P., \& Bernard, J. (2008). The brief resilience scale: assessing the ability to bounce back. International journal of behavioral medicine, 15(3), 194-200.

[32] Snyder, C. R., Cheavens, J., \&Sympson, S. C. (1997). Hope: An individual motive for social commerce. Group dynamics: Theory, research, and practice, 1(2), 107.

[33] Tennant, R., Hiller, L., Fishwick, R., Platt, S., Joseph, S., Weich, S., ... \& Stewart-Brown, S. (2007). The Warwick-Edinburgh mental well-being scale (WEMWBS): development and UK validation. Health and Quality of life Outcomes, 5(1), 63.

[34] Tsukawaki, R., Kojima, N., Imura, T., Furukawa, Y., \& Ito, K. (2019). Relationship between types of humour and stress response and well-being among children in Japan. Asian Journal of Social Psychology, 22(3), 281-289.

[35] Tümkaya, S. (2011). Humor styles and socio-demographic variables as predictor of subjective well-being of turkish university students. Egitim ve Bilim, 36(160), 158.

[36] Wellenzohn, S., Proyer, R. T., \& Ruch, W. (2016). Humor-based online positive psychology interventions: a randomized placebo-controlled long-term trial. The Journal of Positive Psychology, 11(6), 584-594.

[37] Yamamoto, Y., \& Holloway, S. D. (2010). Parental expectations and children's academic performance in sociocultural context. Educational Psychology Review, 22(3), 189-214. 